OPEN ACCESS

Edited by:

Cristiano Fava

University of Verona, Italy

Reviewed by:

Elisa Danese,

University of Verona, Italy Angela Tagetti,

University of Verona, Italy Melania Dovizio,

Università degli Studi "G. d'Annunzio"

Chieti - Pescara, Italy

*Correspondence:

Yogesh A. Kulkarni yogeshkulkarni101@yahoo.com

Specialty section: This article was submitted to Inflammation Pharmacology,

a section of the journal

Frontiers in Pharmacology

Received: 11 June 2017 Accepted: 23 October 2017 Published: 07 November 2017

Citation:

Suryavanshi SV and Kulkarni YA (2017) NF- $\kappa \beta$ : A Potential Target in the Management of Vascular

Complications of Diabetes.

Front. Pharmacol. 8:798.

doi: 10.3389/fphar.2017.00798

\section{NF-k $\beta$ : A Potential Target in the Management of Vascular Complications of Diabetes}

\author{
Sachin V. Suryavanshi and Yogesh A. Kulkarni* \\ Shobhaben Pratapbhai Patel School of Pharmacy and Technology Management, SVKM's Narsee Monjee Institute of \\ Management Studies, Mumbai, India
}

Diabetes is a metabolic disorder affecting large percentage of population worldwide. $N F-\kappa \beta$ plays key role in pathogenesis of vascular complications of diabetes. Persistent hyperglycemia activates NF-к $\beta$ that triggers expression of various cytokines, chemokines and cell adhesion molecules. Over-expression of TNF- $\alpha$, interleukins, TGF$\beta$, Bcl2 and other pro-inflammatory proteins and pro-apoptotic genes by NF-к $\beta$ is key risk factor in vascular dysfunction. NF-к $\beta$ over-expression also triggers calcification of endothelial cells leading to endothelial dysfunction and further vascular complications.

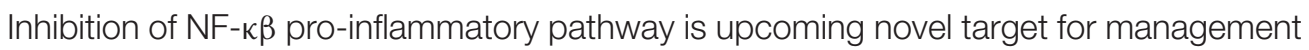
of vascular complications of diabetes. Various natural and synthetic inhibitors of NF$\kappa \beta$ have been studied in management of diabetic complications. Recent preclinical and clinical studies validate NF-к $\beta$ as promising target in the management of vascular complications of diabetes.

Keywords: NF- $\kappa \beta$, diabetic complications, inflammation, nephropathy, neuropathy, retinopathy, cardiomyopathy, NF-к $\beta$ inhibitors

\section{INTRODUCTION}

Diabetes mellitus (DM) and its associated complications are one of the major leading causes of mortality in public worldwide (IDF, 2015; WHO, 2016). The burden of diabetes has increased in India from 5.8 to $8.7 \%$ since year 2000 to 2015 (Unnikrishnan et al., 2016; Pradeepa and Mohan, 2017). Chronic hyperglycemic condition has devastating effects on vasculature that ends into different micro-vascular and macro-vascular complications like neuropathy, nephropathy, retinopathy and cardiomyopathy (He and King, 2004). Increased levels of advanced glycation end products (AGEs), receptors for it (RAGE), oxidative stress, lipoproteins and hyperlipidemia enhance expression of nuclear factor- $\kappa \beta$ (NF- $\kappa \beta$ ) by various pathways. Furthermore, inappropriately expressed NF- $\kappa \beta$ augments apoptosis and inflammatory process that plays principle role in cell injury and further complications (Singh et al., 2014).

The NF- $\kappa \beta$ is a DNA binding protein factor which is involved in transcription of different proinflammatory and inflammatory molecules like cytokines, chemokines, cell adhesion molecules (CAM) and different enzymes (He and King, 2004). The expression of cytokines and inflammatory molecules plays an important role in pathophysiology of diabetes and its associated micro-vascular and macro-vascular complications via modulating different NF- $\kappa \beta$ pathways (Patel and Santani, 2009). 
The current review focuses on role of NF-к $\beta$ in pathophysiology of various vascular complications of diabetes and effect of NF- $\kappa \beta$ inhibitors in the management of same.

\section{NF-к $\beta$ FAMILY}

$\mathrm{NF}-\kappa \beta$ is an evolutionarily conserved protein form the Rel family found in all cell types (Lawrence, 2009). Rel family/NF-к $\beta$ regulates the expression of numerous genes involved in control of various normal cellular and sub-cellular processes like inflammatory and immune responses, cellular growth, cell development and cell survival (Gilmore, 2006; Perkins, 2007). $\mathrm{NF}-\kappa \beta$ is also involved in control of responses to numerous stimuli such as free radicals, stress, cytokines, ultraviolet radiations and viral and bacterial antigens (De Martin et al., 2000; Lawrence, 2009).

The NF- $\beta \beta$ family includes five related transcription factors:

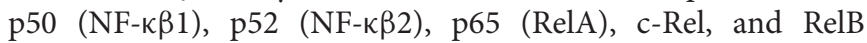

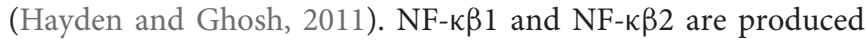
from processing of precursors p105 and p100, respectively (Ghosh and Karin, 2002; Gilmore, 2006; Patel and Santani, 2009). These transcription proteins possess dimerization domain to which DNA binds; Rel homology domain (RHD) at N-terminal facilitates site for dimerization through which they forms homo or hetero-dimers (Ghosh and Karin, 2002; Hayden and Ghosh, 2011). The most copious forms of dimers include p65/p65 homodimers and p65/p50 heterodimers (Birbach et al., 2002). RelA, RelB, and c-Rel contains trans-activation domains (TADs) at C-terminal that allows binding of DNA and activation of target gene expression. Despite this, p50/p105 and p52/p100 do not contains TAD, they participate in target gene expression by forming heterodimers with RelA, RelB or c-Rel (Li and Verma, 2002; Hayden and Ghosh, 2004). Instead of TAD, p50/p105 and p52/p100 contains long ankyrin repeat-containing domain

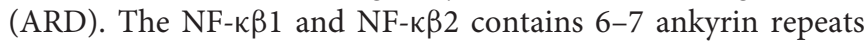
containing 33 amino acid sequences that facilitate site for dimerization (Hayden and Ghosh, 2011; Napetschnig and Wu, 2013).

\section{ACTIVATION OF NF-к $\beta$ FAMILY}

The activation of NF- $\kappa \beta$ is regulated by family of inhibitors

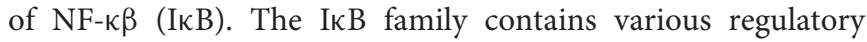

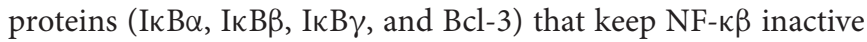
in cytoplasm (Gilmore, 2006; Baker et al., 2011; Hayden and

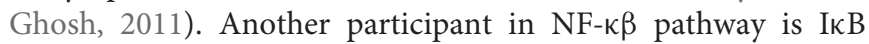
kinase (IKK) complex which catalyzes I $\mathrm{B}$ to release $\mathrm{NF}-\kappa \beta$ (Perkins, 2007). The IKK complex consists of two catalytically active kinases, IKK $\alpha$ (IKK1) and IKK $\beta$ (IKK2) and a regulatory scaffolding protein NF- $\kappa \beta$ essential modifier (NEMO) that keep NF- $\kappa \beta$ inactive in the cytoplasm (Zheng et al., 2010; Liu and Chen, 2011).

The NF- $\kappa \beta$ is activated via two pathways viz. canonical pathway and non-canonical pathway (Zheng et al., 2010; Baker et al., 2011). In canonical pathway when signal is transduced,
NEMO-containing IKK complexes are activated and induce phosphorylation of IKK complex via ubiquitination leading to release of NF- $\kappa \beta$ dimers (Karin and Ben-Neriah, 2000). Furthermore the NF- $\kappa \beta$ dimers enter in the nucleus and modulate target gene expression. In non-canonical pathway, NF$\mathrm{k} \beta$ inducing kinase (NIK) enhance phosphorylation of IKK $\alpha$ and IKK $\beta$, NEMO independently to release NF-к $\beta$ dimers (Hayden and Ghosh, 2011; Liu and Chen, 2011; Shih et al., 2011).

\section{ROLE OF NF- $\kappa \beta$ IN PATHOGENESIS OF VASCULAR COMPLICATIONS}

Prolonged hyperglycemia and insulin resistance are key players in diabetic vascular complications (Ruderman et al., 1992). Hyperglycemia induces formation of AGEs and overproduction of reactive oxygen species (ROS) (Paneni et al., 2013; Tobon-Velasco et al., 2014). The key pathways involved in production of AGEs and ROS due to hyperglycemia includes increased polyol flux, activation of protein kinase C (PKC), increased intracellular formation of AGEs and increased hexosamine flux (Brownlee, 2001, 2005; Xing et al., 2016). Consecutively, ROS and AGEs initiate proinflammatory response and endothelial dysfunction via activation of NF-к $\beta$ (Paneni et al., 2013; Xing et al., 2016). AGEs bind to RAGE present on cell surface of vascular smooth muscles and directly activate NF-к $\beta$ (Lander et al., 1997).

Evidence suggests that activation of NF-к $\beta$ is essential for cell proliferation and cell migration (Bellas et al., 1995). In hyperglycemic condition the NF- $\kappa \beta$ activity is enhanced significantly leading to release of cytokines, TGF- $\beta$, chemokines and vesicular cell adhesion molecules (VCAMs) (Patel and Santani, 2009). Consequently, up-regulation of TNF- $\alpha$, IL1 $\beta$, IL6, CD36, MCP-1 leads to endothelial cell apoptosis and inflammatory process (Reddy and Natarajan, 2011; Evans and Goldfine, 2016). Additionally, over-activated NF-к $\beta$ carry out abnormal transcription of DNA and various genes involved in vascular complications (Zheng et al., 2010). Over-activity of NF- $\kappa \beta$ also leads to altered gene expression of vascular endothelial growth factor (VEGF), platelet-derived growth factor (PDGF), endothelin-1 (ET-1), activated protein C (APC) and transforming growth factor- $\beta$ (TGF- $\beta$ ) that ends in to vascular cell damage and angiogenesis (Kitada et al., 2010).

Increased TNF- $\alpha$, IL- 6 and IL-10 have been observed in adipose tissues in obese rats (de Luca and Olefsky, 2008). TNF- $\alpha$, and cytokines activates NF-к $\beta$ and recruit monocytes producing macrophages $\mathrm{M} 1$ and $\mathrm{M} 2$ that promote $\beta$-cell destruction and insulin resistance. This is key factor in pathophysiology of atherosclerosis (Baker et al., 2011). AGE/RAGE increases vascular calcification through activation NF- $\kappa \beta$ activation and increased expression of TGF- $\beta$, mitogen activated protein kinase (MAPK), and PKC leading to hardening of medial layer of blood vessels (Kay et al., 2016). 


\section{NF- $\kappa \beta$ AND DIABETIC NEPHROPATHY}

Diabetic nephropathy (DN) is the leading cause of cardiovascular mortality and chronic kidney disorder (CKD) in diabetic patients. $\mathrm{DN}$ is characterized by persistent microalbuminuria, decreased glomerular filtration (GFR) rate and increased albumin to creatinine ratio (Reutens and Atkins, 2011). Glomerular changes such as thickening of capillary basement membrane, mesangial expansion and glomerulosclerosis are pathological indications of DN (Patel and Santani, 2009; Lopez-parra et al., 2012). The recent reports endorse about $12-55 \%$ incidences of end stage renal disorders (ESRD) are attributed to diabetes (WHO, 2016). The prevalence of microalbuminuria among diabetic patient in India was found to be $24.3 \%$ (Pradeepa and Mohan, 2017).

Nevertheless, intra-renal inflammation is key factor in pathophysiology of DN. Accumulation of macrophages, monocytes, T-cells, and fibroblasts in diabetic kidney are responsible for inflammation in DN (Bohle et al., 1991; Sakai et al., 2005; Sanz et al., 2010). The activation of NF- $\kappa \beta$ pathways by TNF- $\alpha$ and other cytokines are responsible for accumulation of macrophages in human DN (Sakai et al., 2005; Lenz et al., 2008). There are two sub types of macrophages; M1 and M2. M1 macrophages are involved in pro-inflammatory response while M2 macrophages are involved in tissue repair remodeling and angiogenesis process (Schmid et al., 2006; Silva et al., 2011; Lopez-parra et al., 2012). In diabetic patient, increased AGEs and

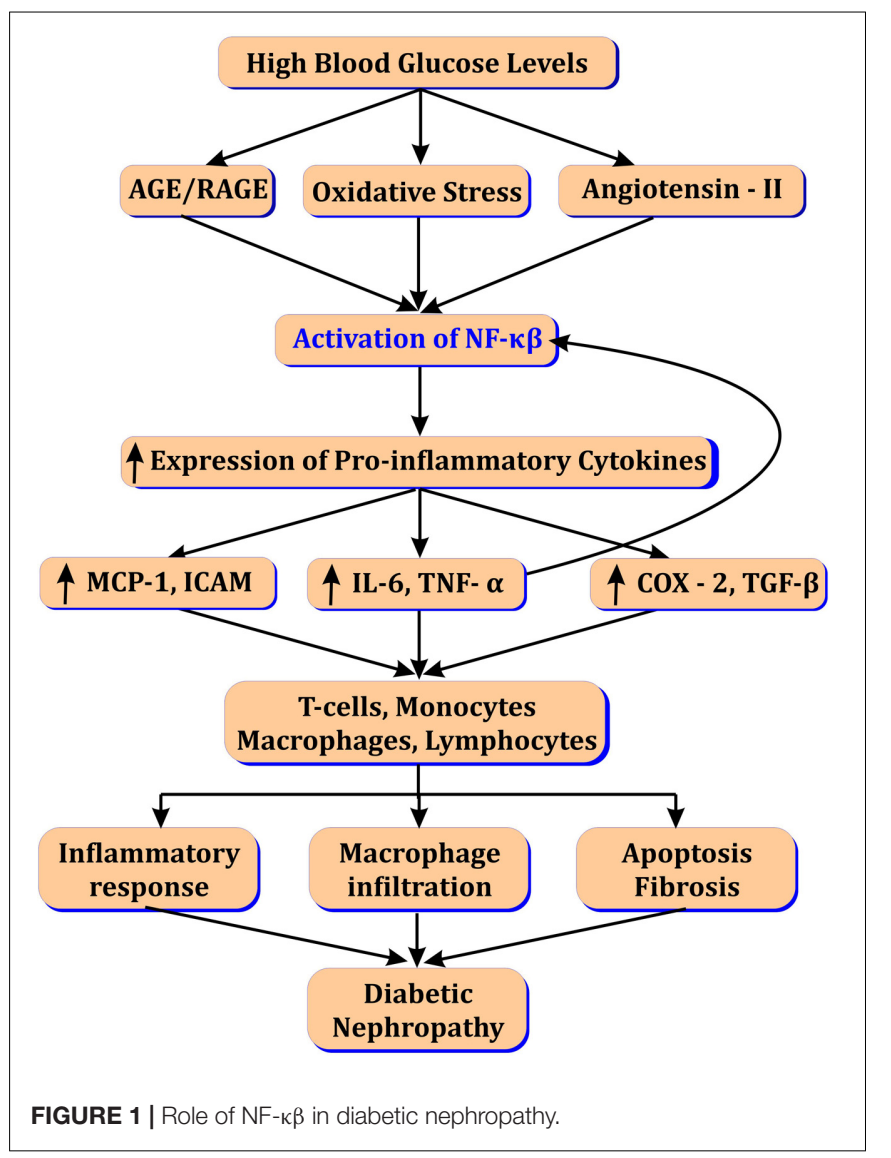

ROS burden activates leukocytes that release superoxide radicals and proteases in the kidney (Mohamed et al., 1999; Patel and Santani, 2009). Additionally, leukocytes up regulate transcription of NF-к $\beta$ in endothelial and mesangial cells (Sanz et al., 2010; Silva et al., 2011; Borgohain et al., 2017).

Activation of NF- $\kappa \beta$ up-regulate monocyte chemoattractant protein-1 (MCP-1) leading to macrophage infiltration (Cha et al., 2005), renal injury and increased microalbuminuria in DN (Lopez-parra et al., 2012). NF- $\beta \beta$ also enhances expression of TGF- $\beta$-activated kinase (TAK-1) from MAPK family known as MAP3K7. In turn TAK1 induce activation of transforming growth factor (TGF- $\beta$ ) leading to extracellular matrix accumulation and fibrosis in the diabetic kidney (Choi et al., 2012; Kanasaki et al., 2013; Meng et al., 2015). MAPK also contribute in gene over-expression of various cytokines and intracellular adhesion molecules (ICAM), c-Jun $\mathrm{NH}_{2}$-terminal kinase (JNK) and leukocyte infiltration via NF- $\kappa \beta$ activation (Sakai et al., 2005; Pan et al., 2013). Renal podocyte injury and podocyte protein accumulation is hallmark of DN. Angiotensin II levels are increased in response to elevated AGEs and oxidized lipids in DN (Figure 1). This in turn, activates NF- $\beta \beta$ via angiotensin $\left(\mathrm{AT}_{1}\right.$ and $\left.\mathrm{AT}_{2}\right)$ receptors and activation of transient receptor potential canonical (TRPC) (Ilatovskaya et al., 2015). NF- $\kappa \beta$ increase calcium influx and ROS canonically in diabetic kidney leading to podocyte protein accumulation and injury (Lee, 2004; Campbell et al., 2011).

\section{NF- $\kappa \beta$ INHIBITORS IN DIABETIC NEPHROPATHY}

Inhibition of NF- $\kappa \beta$ activation may provide treatment option in DN by inhibiting transcription of genes and blocking inflammatory process. A few researchers studied the effect of NF- $\kappa \beta$ inhibition on DN. Curcumin is the active polyphenol component of herbal medicine Curcuma longa well known as turmeric. Curcumin treatment improved DN in type I diabetic rats. It inhibited macrophage infiltration via NF- $\beta \beta$ inhibition.

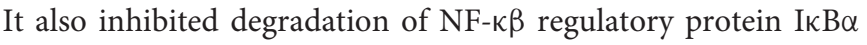
leading to decreased expression of pro-inflammatory (TNF- $\alpha$, IL$1 \beta)$ and profibrotic cytokines (ICAM- 1, MCP- 1 , and TGF- $\beta_{1}$ ) (Soetikno et al., 2011).

Pal and co-workers studied the effect of mangiferin in rats with DN. Mangiferin; a natural C-glucosyl xanthone and polyphenol obtained from bark of Mangifera indica (Mango tree) has antioxidant activity, thereby it inhibited AGEs and oxidative stress mediated pro-inflammatory signaling cascade. Mangiferin inhibited oxidative stress via inhibition of PKC, MAPK and TGF- $\beta$ and improved fibrosis in diabetic kidney. It also reduced expression of pro-apoptotic proteins $\mathrm{Bcl}-3$ and caspase-9 via inhibition of NF- $\beta \beta$ and TNF- $\alpha$. Mangiferin also decreased

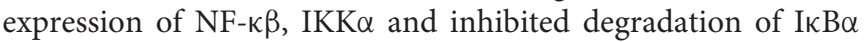
(Pal et al., 2014).

Borgohain and co-workers studied effect of naturally occurring piceatannol on renal inflammation in alloxon-induced DN in rats. Piceatannol is analog of resveratrol and small molecule present in plant Euphorbia lagascae. Piceatannol 
decreased superoxide dismutase (SOD) and glutathione (GSH) and increased malondialdehyde (MDA) and nitric oxide (NO) levels in kidney restoring oxidative stress. Moreover, treatment with piceatannol inhibited NF-kB p65/p50 binding to DNA and reduced renal pro-inflammatory cytokines like TNF- $\alpha$, IL- $1 \beta$ and IL-6 (Borgohain et al., 2017).

$\mathrm{Xu}$ and co-workers studied the effect of resveratrol on renal inflammation and mesangial cell proliferation in streptozotocin induced diabetic mouse. Resveratrol showed renoprotective action via decreasing activation of NF- $\kappa \beta$ and inhibition of Akt and JNK. Moreover resveratrol also inhibited NF- $\kappa \beta$ dependent activation of plasminogen activator inhibitor (PAI-1) and ICAM leading to blockade of pro-apoptotic cascade (Xu et al., 2014).

Liu and co-workers studied the effect of berberine on NF- $\kappa \beta$ pathway in alloxan induced diabetic renal injury in mice. Berberine is an isoquinoline alkaloid isolated from Cortex Phellodendri and Coptidis rhizoma. It has hypolipidemic, antihyperglycemic and antioxidant activity (Singh and Kakkar, 2009). Berberine showed improvement in diabetic renal injury through inhibition of NF- $\kappa \beta$ and thereby down-regulation of ICAM, TGF- $\beta 1$ and fibronectin. It also restored I $\mathrm{B} \alpha$ levels by inhibiting its degradation in kidney tissue. As a result, berberine reduced accumulation of extracellular matrix in kidney cells (Liu et al., 2010).

NF- $\kappa \beta$ activation and macrophage infiltration in adipose tissue has been concerned as key mechanism in development of insulin resistance in diabetic patients (Zamboni et al., 2007). Celastrol, a pentacylic triterpenoid compound isolated from the roots of Celastrus regelii and Tripterygium wilfordii has been studied for its effect on insulin resistance and renal injury in $\mathrm{db} / \mathrm{db}$ mice. Celastrol showed improvement in insulin resistance and renal injury via inhibition of NF- $\kappa \beta$ pathways and inhibiting expression of inflammatory mediators like IFN $\gamma$, NOX4, TLR4, and TNF- $\alpha$ (Kim et al., 2013).

Jianfang and co-workers studied the effect of Paeoniflorin, a natural product obtained from plant Paeonia lactiflora in DN in rats. Paeoniflorin showed improvement in $\mathrm{DN}$ by suppressing expression of iCAM-1 and Collagen - IV via inhibition of NF$\kappa \beta$. It also reduced macrophage infiltration and renal hypertrophy (Jianfang et al., 2009).

Recent studies revealed that (2E,6E)-2,6-bis (2(trifluoromethyl) benzylide-ne)cyclohexanone (C66), a synthesized curcumin analog inhibited JNK2 protein form MAPK family and thereby inhibited NF- $\kappa \beta$ activity and showed reno-protective action by blocking pro-inflammatory cytokines expression (Pan et al., 2013). 1,25-Dihydroxyvitamin D3, a hormonal form of vitamin $\mathrm{D}$ have negative effect on rennin angiotensin system (RAS) and regulate calcium influx in the kidney (Li et al., 2002). 1,25-Dihydroxyvitamin D3 prevented renal injury via inhibition of RAS system and NF- $\kappa \beta$ induced pro-inflammatory cascade (Zhang et al., 2007).

Fenofibrate, an antihyperlipidemic drug and peroxisome proliferator-activated receptor alpha (PPAR $\alpha)$ activator was investigated for anti-inflammatory response through NF- $\beta \beta$ inhibition in DN rats. Fenofibrate treatment reduced expression of NF-к $\beta$ p65, PAI-1, and ICAM-1 along with remarkable improvement in lipid profile in rats through activation of PPAR $\alpha$. Fenofibrate provided renoprotective action via inhibition of NF-к $\beta$ pro-inflammatory pathways (Chen et al., 2008). Thiazolidinedione a PPAR $\alpha$ activator also showed protective effect in renal injury through anti-inflammatory effects mediated by inhibition of NF- $\kappa \beta$ activation in experimental diabetic rats (Ohga et al., 2007). Cerivastatin, a synthetic HMG-CoA reductase inhibitor has been studied for its protective effect in $\mathrm{DN}$ in rats. Cerivastatin showed renoprotective action through inhibition of NF- $\kappa \beta$, ICAM and macrophage infiltration (Usui, 2003).

Curcumin has been proved clinically for its beneficial effects in $\mathrm{DN}$ via inhibition of NF- $\mathrm{\beta} \beta$ in randomized double blind and placebo controlled clinical trial. Oral administration of curcumin attenuated expression of TGF- $\beta$, IL- 8 and proteinuria in type- 2 diabetic patients with nephropathy (Khajehdehi et al., 2011; Lv et al., 2015; Prabhakar, 2017). Administration of alpha lipoic acid in DN patients reduces oxidative stress via inhibition of NF- $\kappa \beta$ and inflammatory cytokines such as TNF- $\alpha$ and IL-8 (Lv et al., 2015).

\section{NF- $\kappa \beta$ AND DIABETIC NEUROPATHY}

Diabetic neuropathy is the most common and stubborn vascular complication of diabetes and major cause of mortality (Boulton et al., 2005). It involves the sensory loss or dysfunction of autonomic, peripheral, somatic sensory and motor nerves (Aslam et al., 2014). Distal polyneuroathy (DPN) and autonomic neuropathy are the most common amongst various types of diabetic neuropathies. Pathological changes include loss of nerve fibers, axonal thickening, demyelination of nerves and neuronal capillary narrowing (Thomas, 1999; Aslam et al., 2014). The prevalence of diabetic neuropathy is higher as compared to other complications (Yagihashi et al., 2011).

The patients with uncontrolled high blood sugar levels experience uncomfortable sensory symptoms especially in lower limbs. The vibration perception threshold and nerve conduction velocity is drastically reduced in diabetic neuropathy (Thomas, 1999; Yagihashi et al., 2007). High blood sugar levels triggers the production of oxidative stress and AGE/RAGE formation in neuronal cells (Vincent et al., 2002; Xing et al., 2016). Increased glycated hemoglobin $\left(\mathrm{HbAc}_{1}\right)$, and stromal collagen level in peripheral nerves, schwann cells and endoneurial vessels is another risk factor for progression of peripheral nerve injury (Sugimoto et al., 1997). Increased AGE/RAGE, ROS, and HbAc in nerve fibers activates apoptosis and insulin resistance via activation of NF- $\kappa \beta$ and release of TNF- $\alpha$ (Haslbeck et al., 2005; Yagihashi et al., 2007, 2011).

Increased polyol flux by aldose reductase contributes in accumulation of sorbitol and generation of ROS in neuronal cells (Brownlee, 2005). Sorbitol and ROS in nerves affects $\mathrm{Na}^{+}, \mathrm{K}^{+}$ ATPase activity that delays nerve conduction velocity (Zhao et al., 2011). NF- $\kappa \beta$ over-expression due to increased ROS, PKC, and AGEs leads to leukocyte infiltration and decreased neuronal growth factor (NGF), IL6, IL1 $\beta$, and TNF- $\alpha$ in nerve cell (Okamoto et al., 2001; Vincent et al., 2002; Pittenger et al., 2003). 
Arachidonic acid pathway is activated in response to NF- $\kappa \beta$ activation that increases COX-2 concentration nerve cells (Yagihashi et al., 2011). Increased oxidative stress activates stress kinase MAPK leading to nerve injury (Tomlinson, 1999). Increased ICAM and NF-к $\beta$ expressions are observed in microvessels of sciatic-tibial nerves of diabetic rats leading to narrowing of vessels and ischemic conditions following inflammatory response (Wang et al., 2006). Peroxisome proliferator-activated receptors (PPARs) are reduced in nerves in response to increased chemokines that enhance gene expression and neuronal death (Figure 2; Freitag and Miller, 2014).

\section{NF- $\kappa \beta$ INHIBITORS IN DIABETIC NEUROPATHY}

Various natural and synthetic NF- $\kappa \beta$ inhibitors have been studied for their protective effect in diabetic neuropathy. Curcumin was studied for its analgesic activity in diabetic neuropathy in mouse (Sharma et al., 2006) and rat (Li et al., 2013). Curcumin inhibited inducible nitric oxide synthase (iNOS) levels and serum TNF$\alpha$ and TNF- $\alpha$ receptor 1 in nerve fiber by inhibiting NF- $\kappa \beta$ expression. Curcumin also reduced neuropoietic cytokines such as IL-1, IL-6 (Joshi et al., 2013).

Another natural compound resveratrol provide neuroprotective and anti-inflammatory activity through

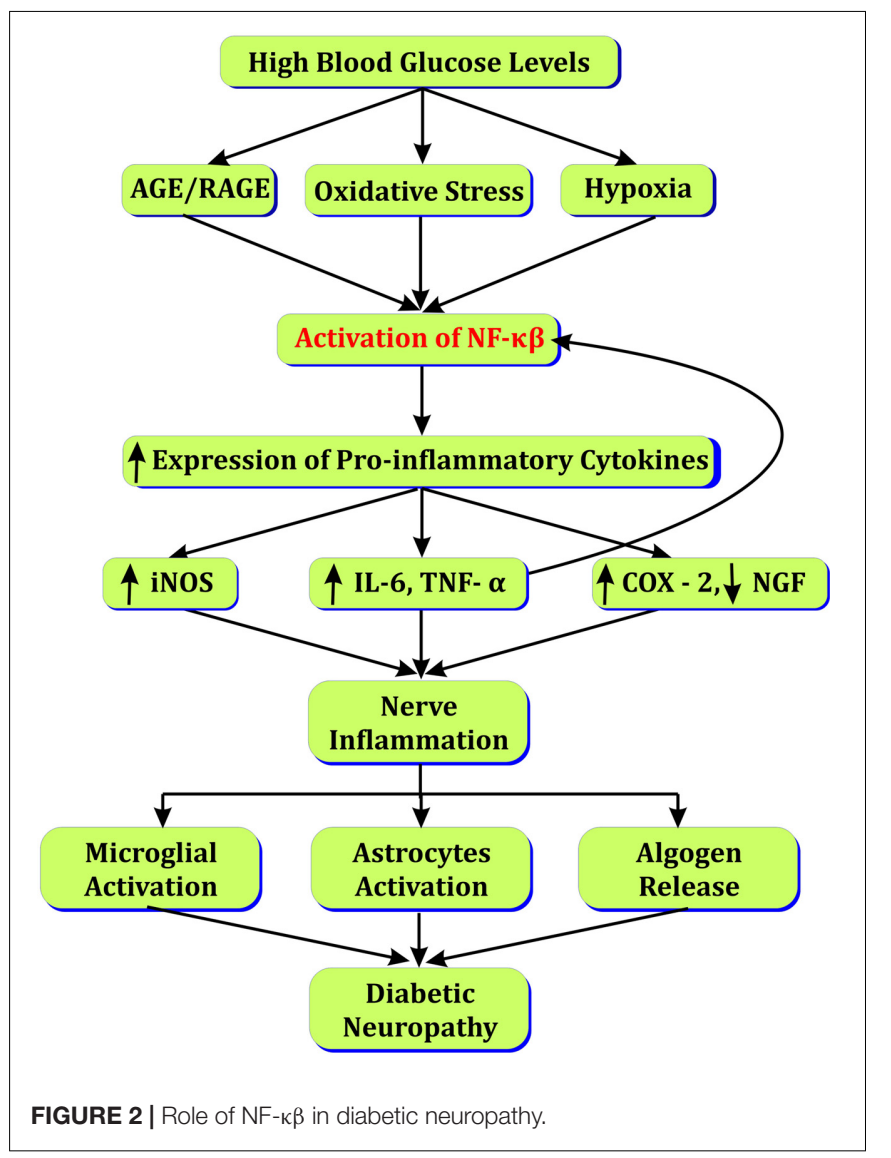

inhibition of NF-к $\beta$ activation (Kumar and Sharma, 2010). Resveratrol also inhibited TNF- $\alpha$, COX-2, and IL-6 levels contributing to NF- $\kappa \beta$ activation. Additionally resveratrol also inhibited degradation of I $\mathrm{B}-\alpha$ protein.

The role of NF- $\kappa \beta$ and erythroid 2-related factor 2 (Nrf2) has been explored in diabetic neuropathy (Li et al., 2008; Ganesh Yerra et al., 2013; Wardyn et al., 2015). It is clear that Nrf2 up-regulation is linked with the NF- $\kappa \beta$ inhibition. Sulforaphane, a natural isothiocyanate present in Brassica oleracea (broccoli) has been studied in diabetic neuropathy. Sulforaphane is a potent inducer of Nrf2 and inhibitor of NF-к $\beta$. Sulforaphane inhibited mechanical hyperalgesia. It also inhibited IKK $\beta$ phosphorylation, IL- 6 and TNF- $\alpha$ levels in sciatic nerve indicating inhibition

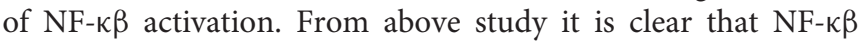
inhibition by sulforaphane provides protective effect in diabetic neuropathy (Negi et al., 2011a).

The traditional herbal medicine Acorus calamus, has been studied for its antihyperglycemic activity, insulin sensitizing activity (Wu et al., 2009) and neuroprotective effect (Muthuraman and Singh, 2011). Alcoholic extract of $A$. calamus showed anti-diabetic activity by suppressing Glucose-6-phosphatase and Fructose-1,6-bisphosphatase enzyme activities (Prisilla et al., 2012). The ethyl acetate fraction of AC showed insulin sensitizing activity by $\alpha$-glucosidase inhibition and PPAR- $\gamma$ agonist activity (Wu et al., 2009). The hydroalcoholic extract of AC attenuate neuropathic pain via its anti-inflammatory property (Muthuraman and Singh, 2011). AC possess anti-inflammatory activity probably via inhibition of NF- $\kappa \beta$ activation (Kim et al., 2009). From literature it can be said that $A$. calamus may provide neuroprotection, and analgesic activity in diabetic neuropathy via inhibition of NF-к $\beta$.

Pioglitazone, a thiazolidinedione derivative and a PPAR- $\gamma$ agonist have been studied in diabetic neuropathy. Pioglitazone inhibited the PKC pathway by activating PPAR- $\gamma$ receptors and improved peripheral nerve function. Pioglitazone also inhibited NF- $\kappa \beta$ activation and MAPK levels in the peripheral nerves and provided anti-inflammatory activity (Yamagishi et al., 2007). Pregabalin, a nutraceutical and first drug approved by FDA for treatment of diabetic neuropathy is a potent NF- $\kappa \beta$ inhibitor. Pregabalin inhibited NF- $\kappa \beta$ activation through nuclear localization of $\mathrm{p} 65$ in nerve cells. It also inhibited $\mathrm{NF}-\kappa \beta$ regulated cytokine and chemokines such as COX-2, TNF- $\alpha$, and IL-6 (Verma et al., 2014).

Melatonin also modulates neuro-inflammation through activation of $\mathrm{Nrf} 2$, inhibition of $\mathrm{NF}-\kappa \beta$ activation and degradation of $\mathrm{I} \kappa \mathrm{B} \alpha$. Treatment with melatonin reduced pro-inflammatory cytokines such as TNF- $\alpha$ and IL- 6 . The COX-2 and iNOS levels were reduced in nerve fibers. The inhibition of NF- $\kappa \beta$ by melatonin reduced DNA fragmentation and improved diabetic neuropathy. The melatonin reduced ROS mediated inflammatory mediators like TNF- $\alpha$, IL-6, and COX-2; thereby DNA fragmentation. Melatonin reduced expression of iNOS and degradation of I $\mathrm{B} \alpha$. Furthermore, melatonin also inhibited NF-к $\beta$ by increasing Nrf2 and heme oxygenase-1 (HO-1) levels in sciatic nerves diabetic rats (Negi et al., 2011b). 
Antioxidants such as alpha lipoic acid reduced oxidative stress and showed anti-inflammatory activity via inhibition of NF- $\mathrm{N} \beta$ (Jeong et al., 2011). Alpha-lipoic acid showed promising results in patients with diabetic neuropathy via inhibition of NF-к $\beta$. Alpha-lipoic acid dose dependently inhibit expression of NF- $\kappa \beta$ and thereby down regulate expression of iCAM and VCAM (Vallianou et al., 2009; Sandireddy et al., 2014).

\section{NF- $\kappa \beta$ AND DIABETIC RETINOPATHY}

Diabetic retinopathy (DR) is one of the most specific microvascular complication and primary cause of blindness in diabetic patients (WHO, 2016). The etiology of DR includes loss of pericytes, capillary basement thickening, microaneurysm, cataract, capillary acellularity, and breakdown of blood-retina barrier (Zhang et al., 2012). Depending on severity, DR is generally classified into proliferative DR (PDR), Non-proliferative DR (NPDR), and diabetic macular edema (DME) (Wu, 2013).

Recent reports state that in 2010, one third of an estimated 285 million people with diabetes have signs of DR (Yau et al., 2012; Lee et al., 2015). It is estimated that the number of people with DR will rise up to 191.0 million by 2030 (IDF, 2015). The prevalence of DR and vision-threatening DR (VTDR) in United States during 2005 to 2008 was estimated to 28.5 and $4.4 \%$, respectively (Zhang et al., 2010). In India, the estimate prevalence of DR reported in clinical examination was 34.1\% (Pradeepa and Mohan, 2017).

The pathogenesis of DR is not so far fully understood, although many mechanisms have been proposed such as accumulation of AGEs, increased aldose reductase activity, increased PKC, increased ROS and increased hexosamine flux (Zhang et al., 2012; Safi et al., 2014). Recent evidences has shown that a chronic low level of inflammation also plays key role in pathogenesis of DR (Antonetti et al., 2006; Tang and Kern, 2011). NF- $\kappa \beta$ present in sub-retinal membranes and microvessels is activated in response to increase ROS and AGEs further activating apoptosis process (Kowluru et al., 2003). The activated NF- $\kappa \beta$ further binds to nuclear DNA and over-express different genes leading to production of free radicals and further cell death (Kowluru et al., 2003).

Activated NF- $\kappa \beta$ also increases expression of different cytokines such as IL-1 $\beta$, IL-6, and IL-8 and pro-apoptotic molecule caspase - 3 in vitreous fluid and serum leading to inflammation mediated cell apoptosis (Yuuki et al., 2001; Kowluru and Odenbach, 2004). Increased inflammatory cascade up-regulate ET-1 and down regulate endothelial nitric oxide synthase (eNOS) further leads to narrowing of blood capillaries, retinal ischemia and blood flow abnormalities (De Martin et al., 2000). Up-regulation of VEGF activates $N F-\kappa \beta$ that triggers angiogenesis process in diabetic rats (De Martin et al., 2000; Joussen et al., 2001). Activated NF-к $\beta$ also over-express intercellular adhesion molecule - 1 (ICAM - 1), fibronectin and CD18 in retinal cells that enhance leukocyte infiltration, retinal fibrosis and blood retinal barrier breakdown (Joussen et al., 2001; Roy et al., 2016). Increased PKC and activated NF- $\beta \beta$ leads to imbalance between proNGF and NGF leading to neuronal dysfunction in the retina (Mysona et al., 2014). Increased polyol flux increase MAPK in renal cells. Furthermore it activates NF- $\kappa \beta$ and enhance trans-activation of TNF- $\alpha$ and COX-2 leading to inflammation (Figure 3; Lorenzi, 2007; Du et al., 2010).

Matrix metalloproteinases (MMPs) also plays an important role in progression of DR. The MMPs, especially MMP-9 is involved in angiogenesis and apoptosis in retinal capillary cells (Kowluru et al., 2012). MMP-9 and MMP-2 are increased in vitreous and retina of diabetic patients and rodents with DR models (Kowluru et al., 2012; Li et al., 2012; Shihab et al., 2015). Activation of NF- $\kappa \beta$, TNF- $\alpha$ and interleukins

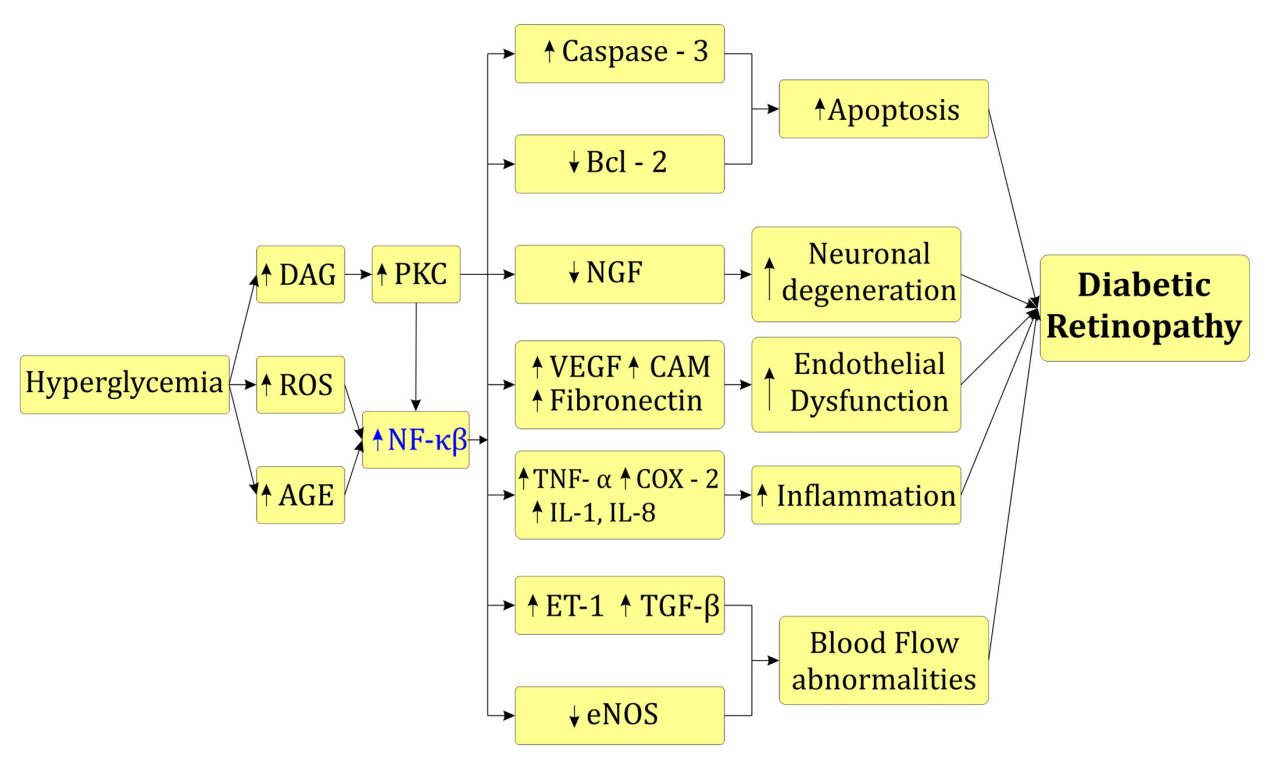

FIGURE 3 | Role of $\mathrm{NF}-\kappa \beta$ in diabetic retinopathy. 
enhance transcription of MMP-9 leading to DNA alkylation and development of DR (Yan and Boyd, 2007; Kowluru et al., 2016).

\section{NF- $\kappa \beta$ INHIBITORS IN DIABETIC RETINOPATHY}

$\mathrm{NF}-\kappa \beta$ activation is responsible for inflammation mediated cell apoptosis, fibrosis and angiogenesis (Jiang et al., 2015). The inhibition of NF- $\kappa \beta$ related may provide promising alternative treatment for DR. Different natural inhibitors of NF- $\kappa \beta$ have been explored for their effect in DR. Treatment with curcumin down-regulated expression of IL-1 $\beta$, VEGF and NF-к $\beta$ and showed significant improvement in DR (Kowluru and Kanwar, 2007).

A clinic based case control study showed that regular Chinese green tea consumption protects $\mathrm{DR}$ via inhibition of NF- $\kappa \beta$ activation. Epigallocatechin-3- gallate; the tannin abundantly present in Chinese green tea inhibits NF- $\beta \beta$ via inhibition of oxidative stress (Ma et al., 2015). Another medicinal herb Salvia miltiorrhiza was explored for its effect in DR. The treatment with S. miltiorrhiza inhibited ICAM-1, toll like receptor-4 (TLR-4) and $N F-\kappa \beta$ in rats with severe acute pancreatitis (Xiping et al., 2009). S. miltiorrhiza also reduced blood sugar, MDA levels and inhibited microaneurysm thereby improved blood retinal barrier in diabetic mice (Zhang et al., 2013). A randomized, double blind, multicenter clinical trial showed that $S$. miltiorrhiza reduced macular edema, neovascularization, venous beading, and cotton spot in patient with DR (Lian et al., 2015). Paeoniflorin, a natural monoterpene glycoside obtained from medicinal plant P. lactiflora was tested for its effect in DR in mice. Paeoniflorin ameliorated DR via inhibition of TLR4/NF- $\kappa \mathrm{B}$ pathway. It also reduced MMP-9 expression and IL-1 $\beta$ level in retinal cells and vitreous (Zhu et al., 2017).

Resolvin D1 a compound derived from w-3-polyunsaturated fatty acid (PUFA) docosahexaenoic acid (DHA) was studied for its effect in DR. The treatment with resolving D1 showed improvement in retinal matrix accumulation via downregulation of NF-к $\beta$. Furthermore it also inhibited expression of pro-inflammatory cytokines IL- $1 \beta$ and IL-18 in retina. Resolving D1 also reduced apoptosis in blood retinal barrier via inhibition of NF-к $\beta$ mediated activation of caspase-3 and leukocyte infiltration (Yin et al., 2017a). The pyrrolidine dithiocarbamate (PDTC) has been explored for in DR. PDTC inhibited NF- $\kappa \beta$ mediated expression of IL- 8 and TNF- $\alpha$ and showed significant effect in DR in mice (Yoshida et al., 1999). Astaxanthin, a natural hydroxycarotenoid abundantly present in sockeye salmon, red trout and algae showed protective effect in DR rats. Astaxanthin reduced expression of ICAM-1, and MCP-1 possibly via inhibition of NF-к $\beta$ (Yeh et al., 2016). Benfotiamine, an S-acyl derivative of thiamine present in vegetables from allium genus prevented DR through blocking NF- $\kappa \beta$ activation by activating transketolase. It also inhibited major three pathways responsible for retinal damage viz. PKC pathway, AGEs pathway, and hexosamine pathway (Hammes et al., 2003).

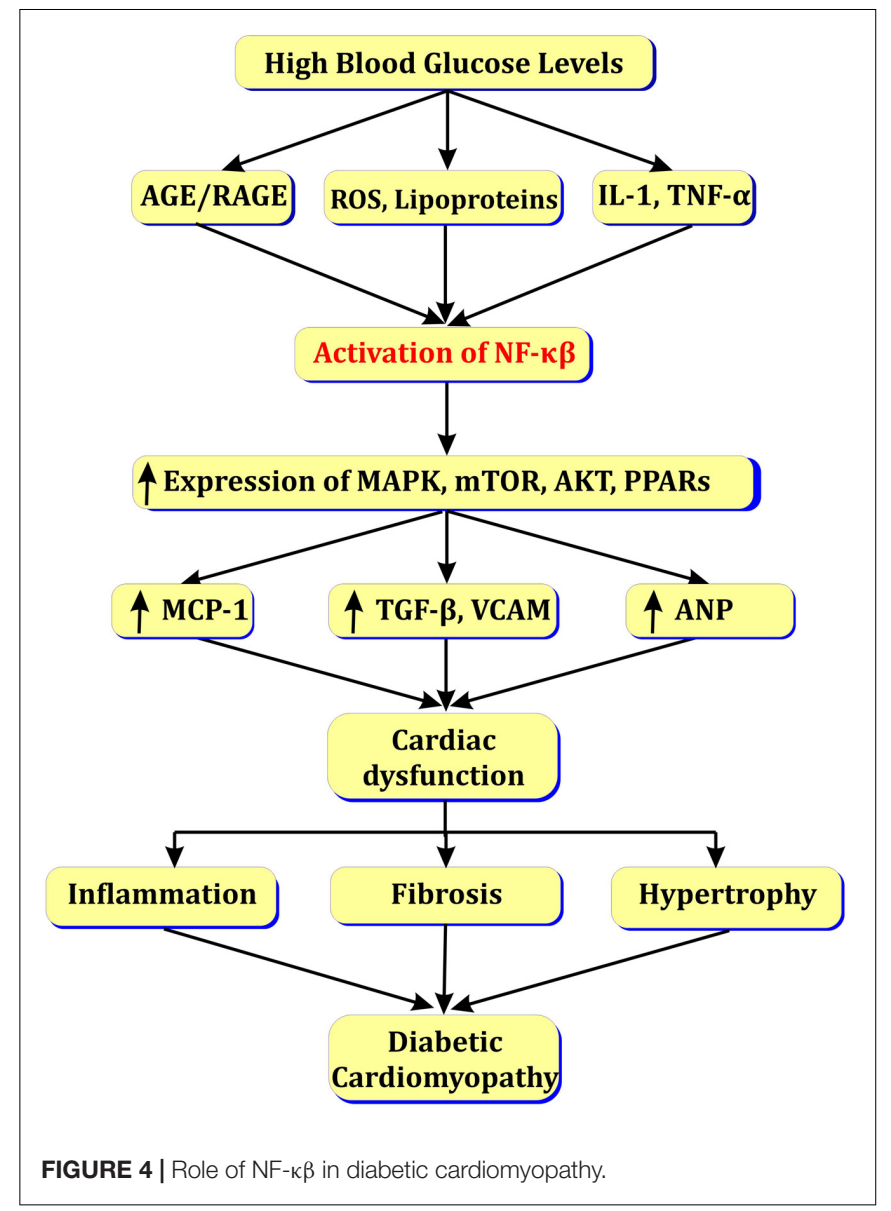

\section{NF- $\kappa \beta$ AND DIABETIC CARDIOMYOPATHY}

Diabetic cardiomyopathy (DC) is the leading cause of mortality in diabetic patients. DC is characterized by systolic and diastolic dysfunction due to reduced contractility, decreased compliance and prolonged relaxation (Patel and Santani, 2009). Increased susceptibility to ischemia/reperfusion injury, accumulation of extracellular matrix and loss of normal micro-vessels are also involved in DC (Bell, 2003; Miki et al., 2013). The number of diabetic patients with cardiovascular complications has been increasing worldwide (Danaei et al., 2011). Some recent studies indicate that the global prevalence of DC in community population is $1.1 \%$. While, $16.9 \%$ diabetic patients met with the criteria for DC and $54.4 \%$ patients had diastolic dysfunction (Dandamudi et al., 2014).

Prolonged hyperglycemia suppresses glucose oxidation, enhances fatty acid metabolism and modulates intracellular signaling that leads to myocardial injury (Miki et al., 2013). The putative mechanisms of DC include insulin resistance, autonomic dysfunction, and myocardial fibrosis. Hyperglycemia induces oxidative stress, AGE/RAGE and galectin-3 levels, and increases TNF- $\alpha$ in myocardial muscles (Patel and Santani, 2009). Increased AGEs and oxidative stress modulate calcium

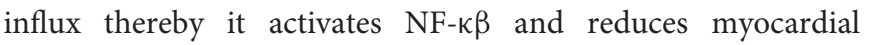


contractility (Fang et al., 2004). The increased ROS activates $\mathrm{NF}-\kappa \beta$ canonically and non-canonically that triggers NF- $\mathrm{N} \beta$ dependent gene expression and production of pro-inflammatory cytokines IL-6, IL-10 and TNF- $\alpha$ in human heart (Esposito et al., 2002; Jones et al., 2003). The cytokines rapidly degrade IкB $\alpha$ and further activates NF- $\kappa \beta$ (Kumar and Sharma, 2010).

Enhanced fatty acid metabolism in diabetic heart increases levels of LDL/VLDL. Further, LDL and VLDL activate NF$\kappa \beta$ and enhance release of vasoactive amines (angiotensin-II, endothelin-1) and TGF- $\beta$ that leads to blood flow abnormalities and myocardial fibrosis (Lorenzo et al., 2011). The activation of NF- $\kappa \beta$ in myocardial cells may induce myocardial hypertrophy via activation of Toll like receptors (TLRs) (Ha et al., 2005) or by activation of angiotensin-II via MAPK/PPAR pathways (see Figure 4; Kawano et al., 2005).

\section{NF- $\kappa \beta$ INHIBITORS IN DIABETIC CARDIOMYOPATHY}

The inhibition of NF-к $\beta$ may provide effective option in treatment of DC. Recent studies showed that inhibition of $N F-\kappa \beta$ inhibits activation of nucleotide-binding oligomerization domain-like receptor protein 3 (NLRP3) and ameliorates DC. NLRP3 inflammasomes takes part in apoptosis process via activation of IL-1 $\beta$ and forming complex with pro-apoptotic molecule caspase-1 and associated speck like protein (ASC). Silencing of NLRP3 leads to inhibition of NF- $\kappa \beta$, activation of IL1 $\beta$ and caspase-1that leads to cardio-protective action (Luo et al., 2014). Very few natural medicines have been explored for their NF-k $\beta$ inhibition and cardio-protective activity.

Ginsenoside Rg1, an active component of herbal medicinal plant Panax ginseng has been studied for its cardio-protective action in diabetic rats. Ginsenoside Rg1 inhibited myocardial cell apoptosis via inhibition of NF- $\kappa \beta$ induced expression of caspase-12 and TNF- $\alpha$ (Yu et al., 2016). The chronic treatment with resveratrol inhibited NF- $\beta \beta$ mediated proinflammatory mediators and cell apoptosis. Resveratrol also reduced oxidative stress by increasing catalase and decreasing MDA levels (Mohammadshahi et al., 2014). Hesperetin, an active component of citrus fruit and natural inhibitor of NF- $\kappa \beta$ showed cardio-protective activity in diabetic rats. Treatment with hesperetin reduced expression of TNF- $\alpha, \mathrm{IL}-1 \beta$ and inhibited

\section{REFERENCES}

Antonetti, D. A., Barber, A. J., Bronson, S. K., Freeman, W. M., Gardner, T. W., Jefferson, L. S., et al. (2006). Diabetic retinopathy: seeing beyond glucoseinduced microvascular disease. Diabetes Metab. Res. Rev. 55, 2401-2411. doi: $10.2337 / \mathrm{db} 05-1635$

Aslam, A., Singh, J., and Rajbhandari, S. (2014). Pathogenesis of painful diabetic neuropathy. Pain Res. Treat. 2014:412041. doi: 10.1155/2014/412041

Baker, R. G., Hayden, M. S., and Ghosh, S. (2011). NF-kB, inflammation, and metabolic disease. Cell Metab. 13, 11-22. doi: 10.1016/j.cmet.2010. 12.008

Bell, D. S. H. (2003). Diabetic cardiomyopathy. Diabetes Care 26, 2949-2951. doi: $10.2337 /$ diacare.26.10.2949 myocardial inflammation. It also reduced expression of ICAM-1, VCAM-1 leading to protection form ischemia/reperfusion injury. Additionally it also inhibited expression of collagen I and III leading to reduction in myocardial fibrosis (Yin et al., 2017b). A novel curcumin analog showed C66 [(2E,6E)2,6-bis(2-(trifluoromethyl) benzylidene) cyclohexanone] showed cardioprotective action via inactivation of NF- $\kappa \beta$. It also inhibited expression of TNF- $\alpha$ and reduced myocardial cell apoptosis (Ren and Sowers, 2014).

\section{CONCLUSION}

Various preclinical studies have been carried out to study the effect of natural NF- $\kappa \beta$ inhibitors in the management of diabetic complications; but its implication in clinical setting is limited. The animal models for diabetic complications depict many clinical features and phenotypes of disease (Chatzigeorgiou et al., 2009). However, no animal model exhibit all features of human diabetic complications. Hence, researchers should consider closely related data such as transcriptomic data, pathological and biochemical data (Betz and Conway, 2016).

NF- $\kappa \beta$ is an important player in pathophysiology of vascular complications of diabetes. Inhibition of NF-к $\beta$ may provide effective treatment option for diabetic vascular complications. There are numerous natural as well as synthetic NF- $\kappa \beta$ inhibitors available but their implications in diabetic complications are very limited. Clinically, NF-к $\beta$ is more focused target to overcome resistance chemotherapy (Godwin et al., 2013), management of cancer (Lin et al., 2010), treatment of inflammation (Calzado et al., 2007). Literature suggests that inflammation is one of the part in pathophysiology of diabetic complications. There are limited number of scientific reports with regard to clinical studies of drug molecules in diabetic complications with special focus on $\mathrm{NF}-\kappa \beta$ as a target. So, there is need to explore potential of NF- $\kappa \beta$ inhibitors for their possible effects in diabetic complications with the help of preclinical studies and clinical set up.

\section{AUTHOR CONTRIBUTIONS}

All authors listed have made a substantial, direct and intellectual contribution to the work, and approved it for publication.

Bellas, R. E., Lee, J. S., and Sonenshein, G. E. (1995). Expression of a constitutive NF-kappa B-like activity is essential for proliferation of cultured bovine vascular smooth muscle cells. J. Clin. Invest. 96, 2521-2527. doi: 10.1172/JCI118313

Betz, B., and Conway, B. R. (2016). An update on the use of animal models in diabetic nephropathy research. Curr. Diab. Rep. 16, 18. doi: 10.1007/s11892015-0706-2

Birbach, A., Gold, P., Binder, B. R., Hofer, E., De Martin, R., and Schmid, J. A. (2002). Signaling molecules of the NF-кB pathway shuttle constitutively between cytoplasm and nucleus. J. Biol. Chem. 277, 10842-10851. doi: 10.1074/ jbc.M112475200

Bohle, A., Wehrmann, M., Bogenschütz, O., Batz, C., Müller, G. A., and Müller, G. A. (1991). The pathogenesis of chronic renal failure in diabetic nephropathy. Pathol. Res. Pract. 187, 251-259. doi: 10.1016/S0344-0338(11)80780-6 
Borgohain, M. P., Lahkar, M., Ahmed, S., Chowdhury, L., Kumar, S., Pant, R., et al. (2017). Small molecule inhibiting nuclear factor- $\mathrm{kB}$ ameliorates oxidative stress and suppresses renal inflammation in early stage of alloxan-induced diabetic nephropathy in rat. Basic Clin. Pharmacol. Toxicol. 120, 442-449. doi: 10.1111/ bcpt.12718

Boulton, A. J. M., Vinik, A. I., Arezzo, J. C., Bril, V., Feldman, E. L., Freeman, R., et al. (2005). Diabetic neuropathies: a statement by the American Diabetes Association. Diabetes Care 28, 956-962. doi: 10.2337/diacare.28.4.956

Brownlee, M. (2001). Biochemistry and molecular cell biology of diabetic complications. Nature 414, 813-820. doi: 10.1038/414813a

Brownlee, M. (2005). The pathobiology of diabetic complications: a unifying mechanism. Diabetes Metab. Res. Rev. 54, 1615-1625. doi: 10.2337/diabetes.54. 6.1615

Calzado, M. A., Bacher, S., and Schmitz, M. L. (2007). NF-кB inhibitors for the treatment of inflammatory diseases and cancer. Curr. Med. Chem. 14, 367-376. doi: 10.2174/092986707779941113

Campbell, K., Raij, L., and Mundel, P. (2011). Role of angiotensin II in the development of nephropathy and podocytopathy of diabetes. Curr. Diabetes Rev. 7, 3-7. doi: 10.2174/157339911794273973

Cha, D. R., Kang, Y. S., Han, S. Y., Jee, Y. H., Han, K. H., Kim, H. K., et al. (2005). Role of aldosterone in diabetic nephropathy. Nephrology 10, 37-39. doi: $10.1111 / \mathrm{j} .1440-1797.2005 .00455 . \mathrm{x}$

Chatzigeorgiou, A., Halapas, A., Kalafatakis, K., and Kamper, E. (2009). The use of animal models in the study of diabetes mellitus. In Vivo 23, 245-258.

Chen, L., Zhang, J., Zhang, Y., Wang, Y., and Wang, B. (2008). Improvement of inflammatory responses associated with NF- $\mathrm{B}$ pathway in kidneys from diabetic rats. Inflamm. Res. 57, 199-204. doi: 10.1007/s00011-006-6190-z

Choi, M. E., Ding, Y., and Kim, S. I. (2012). TGF- $\beta$ signaling via TAK1 pathway: role in kidney fibrosis. Semin. Nephrol. 32, 244-252. doi: 10.1016/j.semnephrol. 2012.04.003

Danaei, G., Finucane, M. M., Lu, Y., Singh, G. M., Cowan, M. J., Paciorek, C. J., et al. (2011). National, regional, and global trends in fasting plasma glucose and diabetes prevalence since 1980: systematic analysis of health examination surveys and epidemiological studies with 370 country-years and 2.7 million participants. Lancet 378, 31-40. doi: 10.1016/S0140-6736(11)60679-X

Dandamudi, S., Slusser, J., Mahoney, D. W., Redfield, M. M., Rodeheffer, R. J., and Chen, H. H. (2014). The prevalence of diabetic cardiomyopathy: a populationbased study in Olmsted County, Minnesota. J. Card. Fail. 20, 304-309. doi: 10.1016/j.cardfail.2014.02.007

de Luca, C., and Olefsky, J. M. (2008). Inflammation and insulin resistance. FEBS Lett. 582, 97-105. doi: 10.1016/j.humov.2008.02.015

De Martin, R., Hoeth, M., Hofer-Warbinek, R., and Schmid, J. A. (2000). The transcription factor NF- B and the regulation of vascular cell function. Arterioscler. Thromb. Vasc. Biol. 20, e83-e88. doi: 10.1161/01.ATV.20. 11.e83

Du, Y., Tang, J., Li, G., Berti-Mattera, L., Lee, C. A., Bartkowski, D., et al. (2010). Effects of p38 MAPK inhibition on early stages of diabetic retinopathy and sensory nerve function. Invest. Ophthalmol. Vis. Sci. 51, 2158-2164. doi: 10.1167/iovs.09-3674

Esposito, K., Nappo, F., Marfella, R., Giugliano, G., Giugliano, F., Ciotola, M., et al. (2002). Inflammatory cytokine concentrations are acutely increased by hyperglycemia in humans: role of oxidative stress. Circulation 106, 2067-2072. doi: 10.1161/01.CIR.0000034509.14906.AE

Evans, J. L., and Goldfine, I. D. (2016). A new road for treating the vascular complications of diabetes: so let's step on the gas. Diabetes Metab. Res. Rev. 65, 346-348. doi: 10.2337/dbi15-0029

Fang, Z. Y., Prins, J. B., and Marwick, T. H. (2004). Diabetic cardiomyopathy: evidence, mechanisms, and therapeutic implications. Endocr. Rev. 25, 543-567. doi: 10.1210/er.2003-0012

Freitag, C. M., and Miller, R. J. (2014). Peroxisome proliferator-activated receptor agonists modulate neuropathic pain: a link to chemokines? Front. Cell. Neurosci. 8:238. doi: 10.3389/fncel.2014.00238

Ganesh Yerra, V., Negi, G., Sharma, S. S., and Kumar, A. (2013). Potential therapeutic effects of the simultaneous targeting of the Nrf2 and NF- $\kappa$ B pathways in diabetic neuropathy. Redox Biol. 1, 394-397. doi: 10.1016/j.redox. 2013.07.005

Ghosh, S., and Karin, M. (2002). Missing pieces in the NF-кB puzzle. Cell 109, 81-96. doi: 10.1016/S0092-8674(02)00703-1
Gilmore, T. D. (2006). Introduction to NF-кB: players, pathways, perspectives. Oncogene 25, 6680-6684. doi: 10.1038/sj.onc.1209954

Godwin, P., Baird, A. M., Heavey, S., Barr, M. P., O’Byrne, K. J., and Gately, K. (2013). Targeting nuclear factor-Kappa B to overcome resistance to chemotherapy. Front. Oncol. 3:120. doi: 10.3389/fonc.2013.00120

Ha, T., Li, Y., Hua, F., Ma, J., Gao, X., Kelley, J., et al. (2005). Reduced cardiac hypertrophy in toll-like receptor 4-deficient mice following pressure overload. Cardiovasc. Res. 68, 224-234. doi: 10.1016/j.cardiores.2005.05.025

Hammes, H.-P., Du, X., Edelstein, D., Taguchi, T., Matsumura, T., Ju, Q., et al. (2003). Benfotiamine blocks three major pathways of hyperglycemic damage and prevents experimental diabetic retinopathy. Nat. Med. 9, 294-299. doi: $10.1038 / \mathrm{nm} 834$

Haslbeck, K. M., Schleicher, E., Bierhaus, A., Nawroth, P., Haslbeck, M., Neundörfer, B., et al. (2005). The AGE/RACE/NF-кB pathway may contribute to the pathogenesis of polyneuropathy in impaired glucose tolerance (IGT). Exp. Clin. Endocrinol. Diabetes 113, 288-291. doi: 10.1055/s-2005-865600

Hayden, M. S., and Ghosh, S. (2004). Signaling to NF-кB. Genes Dev. 18, 2195-2224. doi: 10.1101/gad.1228704.bone

Hayden, M. S., and Ghosh, S. (2011). NF-кB in immunobiology. Cell Res. 21, 223-244. doi: 10.1038/cr.2011.13

He, Z., and King, G. L. (2004). Microvascular complications of diabetes. Endocrinol. Metab. Clin. North Am. 33, 215-238. doi: 10.1016/j.ecl.2003.12.003

IDF (2015). IDF Diabetes Atlas. Brussels: IDF. doi: 10.1289/image.ehp.v119.i03

Ilatovskaya, D. V., Levchenko, V., Lowing, A., Shuyskiy, L. S., Palygin, O., and Staruschenko, A. (2015). Podocyte injury in diabetic nephropathy: implications of angiotensin II - dependent activation of TRPC channels. Sci. Rep. 5:17637. doi: 10.1038/srep 17637

Jeong, I. K., Oh, D. H., Park, S. J., Kang, J. H., Kim, S., Lee, M. S., et al. (2011). Inhibition of NF-кB prevents high glucose-induced proliferation and plasminogen activator inhibitor-1 expression in vascular smooth muscle cells. Exp. Mol. Med. 43, 684-692. doi: 10.3858/emm.2011.43.12.079

Jianfang, F., Yuan, L., Li, W., Bin, G., Nanyan, Z., and Qiuhe, J. (2009). Paeoniflorin prevents diabetic nephropathy in rats. Comp. Med. 59, 557-566.

Jiang, N., Chen, X.-L., Yang, H.-W., and Ma, Y.-R. (2015). Effects of nuclear factor $\kappa \mathrm{B}$ expression on retinal neovascularization and apoptosis in a diabetic retinopathy rat model. Int. J. Ophthalmol. 8, 448-452. doi: 10.3980/j.issn.22223959.2015.03.03

Jones, W. K., Brown, M., Ren, X., He, S., and McGuinness, M. (2003). NF-кB as an integrator of diverse signaling pathways: the heart of myocardial signaling? Cardiovasc. Toxicol. 3, 229-254.

Joshi, R. P., Negi, G., Kumar, A., Pawar, Y. B., Munjal, B., Bansal, A. K., et al. (2013). SNEDDS curcumin formulation leads to enhanced protection from pain and functional deficits associated with diabetic neuropathy: an insight into its mechanism for neuroprotection. Nanomed. Nanotechnol. Biol. Med. 9, 776-785. doi: 10.1016/j.nano.2013.01.001

Joussen, A. M., Murata, T., Tsujikawa, A., Kirchhof, B., Bursell, S.-E., and Adamis, A. P. (2001). Leukocyte-mediated endothelial cell injury and death in the diabetic retina. Am. J. Pathol. 158, 147-152. doi: 10.1016/S0002-9440(10) 63952-1

Kanasaki, K., Taduri, G., and Koya, D. (2013). Diabetic nephropathy: the role of inflammation in fibroblast activation and kidney fibrosis. Front. Endocrinol. 4:7. doi: 10.3389/fendo.2013.00007

Karin, M., and Ben-Neriah, Y. (2000). Phosphorylation meets ubiquitination: the control of NF-кB activity. Annu. Rev. Immunol. 18, 621-663. doi: 10.1146/ annurev.immunol.18.1.621

Kawano, S., Kubota, T., Monden, Y., Kawamura, N., Tsutsui, H., Takeshita, A., et al. (2005). Blockade of NF-kB ameliorates myocardial hypertrophy in response to chronic infusion of angiotensin II. Cardiovasc. Res. 67, 689-698. doi: 10.1016/j. cardiores.2005.04.030

Kay, A. M., Simpson, C. L., and Stewart, J. A. (2016). The role of AGE/RAGE signaling in diabetes-mediated vascular calcification. J. Diabetes Res. 2016:6809703. doi: 10.1155/2016/6809703

Khajehdehi, P., Pakfetrat, M., Javidnia, K., Azad, F., Malekmakan, L., Nasab, M. H., et al. (2011). Oral supplementation of turmeric attenuates proteinuria, transforming growth factor- $\beta$ and interleukin- 8 levels in patients with overt type 2 diabetic nephropathy: a randomized, double-blind and placebocontrolled study. Scand. J. Urol. Nephrol. 45, 365-370. doi: 10.3109/00365599. 2011.585622 
Kim, H., Han, T. H., and Lee, S. G. (2009). Anti-inflammatory activity of a water extract of Acorus calamus L. leaves on keratinocyte HaCaT cells. J. Ethnopharmacol. 122, 149-156. doi: 10.1016/j.jep.2008.12.011

Kim, J. E., Lee, M. H., Nam, D. H., Song, H. K., Kang, Y. S., Lee, J. E., et al. (2013). Celastrol, an NF-kB inhibitor, improves insulin resistance and attenuates renal injury in $\mathrm{db} / \mathrm{db}$ mice. PLOS ONE 8:e62068. doi: 10.1371/journal.pone.0062068

Kitada, M., Zhang, Z., Mima, A., and King, G. L. (2010). Molecular mechanisms of diabetic vascular complications. J. Diabetes Invest. 1, 77-89. doi: 10.1111/j. 2040-1124.2010.00018.x

Kowluru, R. A., and Kanwar, M. (2007). Effects of curcumin on retinal oxidative stress and inflammation in diabetes. Nutr. Metab. 4:8. doi: 10.1186/17437075-4-8

Kowluru, R. A., Koppolu, P., Chakrabarti, S., and Chen, S. (2003). Diabetesinduced activation of nuclear transcriptional factor in the retina, and its inhibition by antioxidants. Free Radic. Res. 37, 1169-1180. doi: 10.1080/ 10715760310001604189

Kowluru, R. A., and Odenbach, S. (2004). Role of interleukin-1 $\beta$ in the development of retinopathy in rats: effect of antioxidants. Invest. Ophthalmol. Vis. Sci. 45, 4161-4166. doi: 10.1167/iovs.04-0633

Kowluru, R. A., Shan, Y., and Mishra, M. (2016). Dynamic DNA methylation of matrix metalloproteinase-9 in the development of diabetic retinopathy. Lab. Invest. 96, 1040-1049. doi: 10.1038/labinvest.2016.78

Kowluru, R. A., Zhong, Q., and Santos, J. M. (2012). Matrix metalloproteinases in diabetic retinopathy: potential role of MMP-9. Expert Opin. Invest. Drugs 21, 797-805. doi: 10.1517/13543784.2012.681043

Kumar, A., and Sharma, S. S. (2010). NF-кB inhibitory action of resveratrol: a probable mechanism of neuroprotection in experimental diabetic neuropathy. Biochem. Biophys. Res. Commun. 394, 360-365. doi: 10.1016/j.bbrc.2010.03.014

Lander, H. M., Tauras, J. M., Ogiste, J. S., Hori, O., Moss, R. A., and Schmidt, A. M. (1997). Activation of the receptor for advanced glycation end products triggers a p21ras-dependent mitogen-activated protein kinase pathway regulated by oxidant stress. J. Biol. Chem. 272, 17810-17814. doi: 10.1074/jbc.272.28.17810

Lawrence, T. (2009). The nuclear factor NF-кB pathway in inflammation. Cold Spring Harb. Perspect. Biol. 1:a001651. doi: 10.1101/cshperspect.a001651

Lee, F. T. H. (2004). Interactions between angiotensin II and NF- B-dependent pathways in modulating macrophage infiltration in experimental diabetic nephropathy. J. Am. Soc. Nephrol. 15, 2139-2151. doi: 10.1097/01.ASN. 0000135055.61833.A8

Lee, R., Wong, T. Y., and Sabanayagam, C. (2015). Epidemiology of diabetic retinopathy, diabetic macular edema and related vision loss. Eye Vis. 2, 17. doi: 10.1186/s40662-015-0026-2

Lenz, O., Fornoni, A., Ijaz, A., and Tejada, T. (2008). Role of inflammation in diabetic nephropathy. Curr. Diabetes Rev. 4, 10-17. doi: 10.2174/ 157339908783502361

Li, Q., and Verma, I. M. (2002). NF-кB regulation in the immune system. Nat. Rev. Immunol. 2, 725-734. doi: 10.1038/nri910

Li, W., Khor, T. O., Xu, C., Shen, G., Jeong, W.-S., Yu, S., et al. (2008). Activation of Nrf2-antioxidant signaling attenuates NFKB-inflammatory response and elicits apoptosis. Biochem. Pharmacol. 76, 1485-1489. doi: 10.1016/j.bcp.2008.07.017

Li, Y., Zhang, Y., Liu, D. B., Liu, H. Y., Hou, W. G., and Dong, Y. S. (2013). Curcumin attenuates diabetic neuropathic pain by downregulating TNF- $\alpha$ in a rat model. Int. J. Med. Sci. 10, 377-381. doi: 10.7150/ijms.5224

Li, Y. C., Kong, J., Wei, M., Chen, Z.-F., Liu, S. Q., and Cao, L.-P. (2002). 1,25 -Dihydroxyvitamin D3 is a negative endocrine regulator of the reninangiotensin system. J. Clin. Invest. 110, 229-238. doi: 10.1172/JCI20021 5219

Li, Y. F., Xu, X. B., Chen, X. H., Wei, G., He, B., and Wang, J. D. (2012). The nuclear factor- B pathway is involved in matrix metalloproteinase- 9 expression in RU486-induced endometrium breakdown in mice. Hum. Reprod. 27, 2096-2106. doi: 10.1093/humrep/des110

Lian, F., Wu, L., Tian, J., Jin, M., Zhou, S., Zhao, M., et al. (2015). The effectiveness and safety of a danshen-containing Chinese herbal medicine for diabetic retinopathy: a randomized, double-blind, placebo-controlled multicenter clinical trial. J. Ethnopharmacol. 164, 71-77. doi: 10.1016/j.jep.2015. 01.048

Lin, Y., Bai, L., Chen, W., and Xu, S. (2010). The NF-кB activation pathways, emerging molecular targets for cancer prevention and therapy. Expert Opin. Ther. Targets 14, 45-55. doi: 10.1517/14728220903431069
Liu, S., and Chen, Z. J. (2011). Expanding role of ubiquitination in NF- $\mathrm{kB}$ signaling. Cell Res. 21, 6-21. doi: 10.1038/cr.2010.170

Liu, W., Zhang, X., Liu, P., Shen, X., Lan, T., Li, W., et al. (2010). Effects of berberine on matrix accumulation and NF- $\mathrm{KB}$ signal pathway in alloxaninduced diabetic mice with renal injury. Eur. J. Pharmacol. 638, 150-155. doi: 10.1016/j.ejphar.2010.04.033

Lopez-parra, V., Mallavia, B., Egido, J., and Gomez-guerrero, C. (2012). "Immunoinflammation in diabetic nephropathy: molecular mechanisms and therapeutic options," in Diabetic Nephropathy, ed. J. S. D. Chan (Rijeka: InTech).

Lorenzi, M. (2007). The polyol pathway as a mechanism for diabetic retinopathy: attractive, elusive, and resilient. Exp. Diabetes Res. 2007:61038. doi: 10.1155/ 2007/61038

Lorenzo, O., Picatoste, B., Ares-Carrasco, S., Ramírez, E., Egido, J., and Tuñon, J. (2011). Potential role of nuclear factor $\mathrm{\kappa B}$ in diabetic cardiomyopathy. Mediators Inflamm. 2011:652097. doi: 10.1155/2011/652097

Luo, B., Li, B., Wang, W., Liu, X., Xia, Y., Zhang, C., et al. (2014). NLRP3 gene silencing ameliorates diabetic cardiomyopathy in a type 2 diabetes rat model. PLOS ONE 9:e104771. doi: 10.1371/journal.pone.0104771

Lv, M., Chen, Z., Hu, G., and Li, Q. (2015). Therapeutic strategies of diabetic nephropathy: recent progress and future perspectives. Drug Discov. Today 20, 332-346. doi: 10.1016/j.drudis.2014.10.007

Ma, Q., Chen, D., Sun, H.-P., Yan, N., Xu, Y., and Pan, C.-W. (2015). Regular Chinese green tea consumption is protective for diabetic retinopathy: a clinicbased case-control study. J. Diabetes Res. 2015:231570. doi: 10.1155/2015/ 231570

Meng, X. M., Tang, P. M. K., Li, J., and Lan, H. Y. (2015). TGF- $\beta /$ Smad signaling in renal fibrosis. Front. Physiol. 6:82. doi: 10.3389/fphys.2015.00082

Miki, T., Yuda, S., Kouzu, H., and Miura, T. (2013). Diabetic cardiomyopathy: pathophysiology and clinical features. Heart Fail. Rev. 18, 149-166. doi: 10.1007/s10741-012-9313-3

Mohamed, A. K., Bierhaus, A., Schiekofer, S., Tritschler, H., Ziegler, R., and Nawroth, P. P. (1999). The role of oxidative stress and NF-кB activation in late diabetic complications. Biofactors 10, 157-167. doi: 10.1002/biof.5520100211

Mohammadshahi, M., Haidari, F., and Soufi, F. G. (2014). Chronic resveratrol administration improves diabetic cardiomyopathy in part by reducing oxidative stress. Cardiol. J. 21, 39-46. doi: 10.5603/CJ.a2013.0051

Muthuraman, A., and Singh, N. (2011). Attenuating effect of Acorus calamus extract in chronic constriction injury induced neuropathic pain in rats: an evidence of anti-oxidative, anti-inflammatory, neuroprotective and calcium inhibitory effects. BMC Complement. Altern. Med. 11:24. doi: 10.1186/14726882-11-24

Mysona, B. A., Shanab, A. Y., Elshaer, S. L., and El-Remessy, A. B. (2014). Nerve growth factor in diabetic retinopathy: beyond neurons. Expert Rev. Ophthalmol. 9, 99-107. doi: 10.1586/17469899.2014.903157

Napetschnig, J., and Wu, H. (2013). Molecular basis of NF-кB signaling. Annu. Rev. Biophys. 42, 443-468. doi: 10.1146/annurev-biophys-083012-130338

Negi, G., Kumar, A., and Sharma, S. S. (2011a). Nrf2 and NF-кB modulation by sulforaphane counteracts multiple manifestations of diabetic neuropathy in rats and high glucose-induced changes. Curr. Neurovasc. Res. 8, 294-304. doi: 10.2174/156720211798120972

Negi, G., Kumar, A., and Sharma, S. S. (2011b). Melatonin modulates neuroinflammation and oxidative stress in experimental diabetic neuropathy: effects on NF-kB and Nrf2 cascades. J. Pineal Res. 50, 124-131. doi: 10.1111/j. 1600-079X.2010.00821.x

Ohga, S., Shikata, K., Yozai, K., Okada, S., Ogawa, D., Usui, H., et al. (2007). Thiazolidinedione ameliorates renal injury in experimental diabetic rats through anti-inflammatory effects mediated by inhibition of NF-кB activation. Am. J. Physiol. 292, F1141-F1150. doi: 10.1152/ajprenal.00288.2005

Okamoto, K., Martin, D. P., Schmelzer, J. D., Mitsui, Y., and Low, P. A. (2001). Proand anti-inflammatory cytokine gene expression in rat sciatic nerve chronic constriction injury model of neuropathic pain. Exp. Neurol. 169, 386-391. doi: 10.1006/exnr.2001.7677

Pal, P. B., Sinha, K., and Sil, P. C. (2014). Mangiferin attenuates diabetic nephropathy by inhibiting oxidative stress mediated signaling cascade, TNF $\alpha$ related and mitochondrial dependent apoptotic pathways in streptozotocininduced diabetic rats. PLOS ONE 9:e107220. doi: 10.1371/journal.pone.0107220 Pan, Y., Zhang, X., Wang, Y., Cai, L., Ren, L., Tang, L., et al. (2013). Targeting JNK by a new curcumin analog to inhibit NF-kB-mediated expression of cell 
adhesion molecules attenuates renal macrophage infiltration and injury in diabetic mice. PLOS ONE 8:e79084. doi: 10.1371/journal.pone.0079084

Paneni, F., Beckman, J. A., Creager, M. A., and Cosentino, F. (2013). Diabetes and vascular disease: pathophysiology, clinical consequences, and medical therapy: part I. Eur. Heart J. 34, 2436-2446. doi: 10.1093/eurheartj/eht149

Patel, S., and Santani, D. (2009). Role of NF-kB in the pathogenesis of diabetes and its associated complications. Pharmacol. Rep. 61, 595-603. doi: 10.1016/S17341140(09)70111-2

Perkins, N. D. (2007). Integrating cell-signalling pathways with NF-кB and IKK function. Nat. Rev. Mol. Cell Biol. 8, 49-62. doi: 10.1038/nrm2083

Pittenger, G., Vinik, A., and Pittenger, G. L. (2003). Nerve growth factor and diabetic neuropathy. Exp. Diabesity Res. 4, 271-285. doi: 10.1080/ 15438600390249718

Prabhakar, S. S. (2017). Effects of curcumin in experimental diabetic nephropathy. J. Invest. Med. 65, 1-6. doi: 10.1136/jim-2016-000272

Pradeepa, R., and Mohan, V. (2017). Prevalence of type 2 diabetes and its complications in India and economic costs to the nation. Eur. J. Clin. Nutr. 71, 816-824. doi: 10.1038/ejcn.2017.40

Prisilla, D. H., Balamurugan, R., and Shah, H. R. (2012). Antidiabetic activity of methanol extract of Acorus calamus in STZ induced diabetic rats. Asian Pac. J. Trop. Biomed. 2, S941-S946. doi: 10.1016/S2221-1691(12)60341-4

Reddy, M. A., and Natarajan, R. (2011). Epigenetic mechanisms in diabetic vascular complications. Cardiovasc. Res. 90, 421-429. doi: 10.1093/cvr/cvr024

Ren, J., and Sowers, J. R. (2014). Application of a novel curcumin analog in the management of diabetic cardiomyopathy. Diabetes Metab. Res. Rev. 63, 3166-3168. doi: $10.2337 / \mathrm{db} 14-0863$

Reutens, A. T., and Atkins, R. C. (2011). Epidemiology of diabetic nephropathy. Contrib. Nephrol. 170, 1-7. doi: 10.1159/000324934

Roy, S., Amin, S., and Roy, S. (2016). Retinal fibrosis in diabetic retinopathy. Exp. Eye Res. 142, 71-75. doi: 10.1016/j.exer.2015.04.004

Ruderman, N. B., Williamson, J. R., and Brownlee, M. (1992). Glucose and diabetic vascular disease. FASEB J. 6, 2905-2914. doi: 10.1096/fj.1530-6860

Safi, S. Z., Qvist, R., Kumar, S., Batumalaie, K., and Ismail, I. S. (2014). Molecular mechanisms of diabetic retinopathy, general preventive strategies, and novel therapeutic targets. Biomed Res. Int. 2014:801269. doi: 10.1155/2014/ 801269

Sakai, N., Wada, T., Furuichi, K., Iwata, Y., Yoshimoto, K., Kitagawa, K., et al. (2005). Involvement of extracellular signal-regulated kinase and p38 in human diabetic nephropathy. Am. J. Kidney Dis. 45, 54-65. doi: 10.1053/j.ajkd.2004. 08.039

Sandireddy, R., Ganesh Yerra, K., Areti, A., Komirishetty, P., Kumar, A., Yerra, V. G., et al. (2014). Neuroinflammation and oxidative stress in diabetic neuropathy. Futuristic strategies based on these targets. Int. J. Endocrinol. 2014:674987. doi: 10.1155/2014/674987

Sanz, A. B., Sanchez-Nino, M. D., Ramos, A. M., Moreno, J. A., Santamaria, B.,

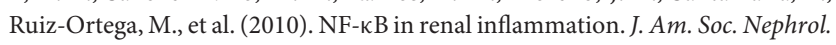
21, 1254-1262. doi: 10.1681/ASN.2010020218

Schmid, H., Boucherot, A., Yasuda, Y., Henger, A., Brunner, B., Eichinger, F., et al. (2006). Modular activation of nuclear factor- $\mathrm{B}$ transcriptional programs in human diabetic nephropathy. Diabetes Metab. Res. Rev. 55, 2993-3003. doi: $10.2337 / \mathrm{db} 06-0477$

Sharma, S., Kulkarni, S. K., Agrewala, J. N., and Chopra, K. (2006). Curcumin attenuates thermal hyperalgesia in a diabetic mouse model of neuropathic pain. Eur. J. Pharmacol. 536, 256-261. doi: 10.1016/j.ejphar.2006.03.006

Shih, V. F.-S., Tsui, R., Caldwell, A., and Hoffmann, A. (2011). A single NFkB system for both canonical and non-canonical signaling. Cell Res. 21, 86-102. doi: 10.1038/cr.2010.161

Shihab, P. K., Al-Roub, A., Al-Ghanim, M., Al-Mass, A., Behbehani, K., and Ahmad, R. (2015). TLR2 and AP-1/NF- $\mathrm{KB}$ are involved in the regulation of MMP-9 elicited by heat killed Listeria monocytogenes in human monocytic THP-1 cells. J. Inflamm. 12, 32. doi: 10.1186/s12950-015-0077-0

Silva, G. E. B., Costa, R. S., Ravinal, R. C., Ramalho, L. Z., Dos Reis, M. A., Coimbra, T. M., et al. (2011). NF-kB expression in IgA nephropathy outcome. Dis. Markers 31, 9-15. doi: 10.3233/DMA-2011-0795

Singh, J., and Kakkar, P. (2009). Antihyperglycemic and antioxidant effect of Berberis aristata root extract and its role in regulating carbohydrate metabolism in diabetic rats. J. Ethnopharmacol. 123, 22-26. doi: 10.1016/j.jep.2009. 02.038
Singh, V. P., Bali, A., Singh, N., and Jaggi, A. S. (2014). Advanced glycation end products and diabetic complications. Korean J. Physiol. Pharmacol. 18, 1-14. doi: 10.4196/kjpp.2014.18.1.1

Soetikno, V., Sari, F. R., Veeraveedu, P. T., Thandavarayan, R. A., Harima, M., Sukumaran, V., et al. (2011). Curcumin ameliorates macrophage infiltration by inhibiting NF- $\mathrm{KB}$ activation and proinflammatory cytokines in streptozotocin induced-diabetic nephropathy. Nutr. Metab. 8:35. doi: 10.1186/1743-7075-8-35

Sugimoto, K., Nishizawa, Y., Horiuchi, S., and Yagihashi, S. (1997). Localization in human diabetic peripheral nerve of $\mathrm{N}$ (epsilon)-carboxymethyllysine-protein adducts, an advanced glycation endproduct. Diabetologia 40, 1380-1387. doi: $10.1007 / \mathrm{s} 001250050839$

Tang, J., and Kern, T. S. (2011). Inflammation in diabetic retinopathy. Prog. Retin. Eye Res. 30, 343-358. doi: 10.1016/j.preteyeres.2011.05.002

Thomas, P. K. (1999). Diabetic neuropathy: mechanisms and future treatment options. J. Neurol. Neurosurg. Psychiatry 67, 277-279. doi: 10.1136/jnnp.67. 3.277

Tobon-Velasco, J., Cuevas, E., and Torres-Ramos, M. (2014). Receptor for AGEs (RAGE) as mediator of NF-kB pathway activation in neuroinflammation and oxidative stress. CNS Neurol. Disord. Drug Targets 13, 1615-1626. doi: 10.2174/ 1871527313666140806144831

Tomlinson, D. R. (1999). Mitogen-activated protein kinases as glucose transducers for diabetic complications. Diabetologia 42, 1271-1281. doi: 10.1007/ s001250051439

Unnikrishnan, R., Anjana, R. M., and Mohan, V. (2016). Diabetes mellitus and its complications in India. Nat. Rev. Endocrinol. 12, 357-370. doi: 10.1038/nrendo. 2016.53

Usui, H. (2003). HMG-CoA reductase inhibitor ameliorates diabetic nephropathy by its pleiotropic effects in rats. Nephrol. Dial. Transplant. 18, 265-272. doi: $10.1093 / \mathrm{ndt} / 18.2 .265$

Vallianou, N., Evangelopoulos, A., and Koutalas, P. (2009). Alpha-lipoic Acid and diabetic neuropathy. Rev. Diabet. Stud. 6, 230-236. doi: 10.1900/RDS.2009. 6.230

Verma, V., Singh, N., and Singh Jaggi, A. (2014). Pregabalin in neuropathic pain: evidences and possible mechanisms. Curr. Neuropharmacol. 12, 44-56. doi: 10.2174/1570159X1201140117162802

Vincent, A. M., Brownlee, M., and Russel, J. W. (2002). Oxidative stress and programmed cell death in diabetic neuropathy. Ann. N. Y. Acad. Sci. 959, 368-383. doi: 10.1111/j.1749-6632.2002.tb02108.x

Wang, Y., Schmeichel, A. M., Iida, H., Schmelzer, J. D., and Low, P. A. (2006). Enhanced inflammatory response via activation of NF-kB in acute experimental diabetic neuropathy subjected to ischemia-reperfusion injury. J. Neurol. Sci. 247, 47-52. doi: 10.1016/j.jns.2006.03.011

Wardyn, J. D., Ponsford, A. H., and Sanderson, C. M. (2015). Dissecting molecular cross-talk between Nrf2 and NF-kB response pathways. Biochem. Soc. Trans. 43, 621-626. doi: 10.1042/BST20150014

WHO (2016). Global Report on Diabetes. Geneva: WHO.

Wu, H. S., Zhu, D. F., Zhou, C. X., Feng, C. R., Lou, Y. J., Yang, B., et al. (2009). Insulin sensitizing activity of ethyl acetate fraction of Acorus calamus L. in vitro and in vivo. J. Ethnopharmacol. 123, 288-292. doi: 10.1016/j.jep.2009. 03.004

Wu, L. (2013). Classification of diabetic retinopathy and diabetic macular edema. World J. Diabetes 4:290. doi: 10.4239/wjd.v4.i6.290

Xing, L., Gao Hong, L., Dai, G. Y., Sun, H. M., and Xu, H. Q. (2016). Foodadvanced glycation end products aggravate the diabetic vascular complications via modulating the AGEs/RAGE pathway. Chin. J. Nat. Med. 14, 844-855. doi: 10.1016/S1875-5364(16)30101-7

Xiping, Z., Dijiong, W., Jianfeng, L., Qihui, C., Jing, Y., Penghui, J., et al. (2009). Effects of salvia miltiorrhizae on ICAM-1, TLR4, NF-kB and bax proteins expression in multiple organs of rats with severe acute pancreatitis or obstructive jaundice. Inflammation 32, 218-232. doi: 10.1007/s10753-0099124-4

Xu, F., Wang, Y., Cui, W., Yuan, H., Sun, J., Wu, M., et al. (2014). Resveratrol prevention of diabetic nephropathy is associated with the suppression of renal inflammation and mesangial cell proliferation: possible roles of Akt/NF- $\kappa$ B pathway. Int. J. Endocrinol. 2014:289327. doi: 10.1155/2014/289327

Yagihashi, S., Mizukami, H., and Sugimoto, K. (2011). Mechanism of diabetic neuropathy: where are we now and where to go? J. Diabetes Invest. 2, 18-32. doi: 10.1111/j.2040-1124.2010.00070.x 
Yagihashi, S., Yamagishi, S.-I., and Wada, R. (2007). Pathology and pathogenetic mechanisms of diabetic neuropathy: correlation with clinical signs and symptoms. Diabetes Res. Clin. Pract. 77, S184-S189. doi: 10.1016/j.diabres. 2007. 01.054

Yamagishi, S.-I., Ogasawara, S., Mizukami, H., Yajima, N., Wada, R., Sugawara, A., et al. (2007). Correction of protein kinase $\mathrm{C}$ activity and macrophage migration in peripheral nerve by pioglitazone, peroxisome proliferator activated- $\gamma$-ligand, in insulin-deficient diabetic rats. J. Neurochem. 104, 491-499. doi: 10.1111/j. 1471-4159.2007.05050.x

Yan, C., and Boyd, D. D. (2007). Regulation of matrix metalloproteinase gene expression. J. Cell. Physiol. 211, 19-26. doi: 10.1002/jcp.20948

Yau, J. W. Y., Rogers, S. L., Kawasaki, R., Lamoureux, E. L., Kowalski, J. W., Bek, T., et al. (2012). Global prevalence and major risk factors of diabetic retinopathy. Diabetes Care 35, 556-564. doi: 10.2337/dc11-1909

Yeh, P.-T., Huang, H.-W., Yang, C.-M., Yang, W.-S., and Yang, C.-H. (2016). Astaxanthin inhibits expression of retinal oxidative stress and inflammatory mediators in streptozotocin-induced diabetic rats. PLOS ONE 11:e0146438. doi: 10.1371/journal.pone.0146438

Yin, Y., Chen, F., Wang, W., Wang, H., and Zhang, X. (2017a). Resolvin D1 inhibits inflammatory response in STZ-induced diabetic retinopathy rats : possible involvement of NLRP3 inflammasome and NF-кB signaling pathway. Mol. Vis. 23, 242-250.

Yin, Y., Xu, Y., Ma, H., and Tian, X. (2017b). Hesperetin ameliorates cardiac inflammation and cardiac fibrosis in streptozotocin-induced diabetic rats by inhibiting NF-кB signaling pathway. Biomed. Res. 28, 223-229.

Yoshida, A., Yoshida, S., Ishibashi, T., and Kuwano, M. (1999). Suppression of retinal neovascularization by the NF- $\mathrm{kB}$ inhibitor pyrrolidine dithiocarbamate in mice. Invest. Ophthalmol. Vis. Sci. 40, 1624-1629.

Yu, H., Zhen, J., Yang, Y., Gu, J., Wu, S., and Liu, Q. (2016). Ginsenoside Rg1 ameliorates diabetic cardiomyopathy by inhibiting endoplasmic reticulum stress-induced apoptosis in a streptozotocin-induced diabetes rat model. J. Cell. Mol. Med. 20, 623-631. doi: 10.1111/jcmm.12739

Yuuki, T., Kanda, T., Kimura, Y., Kotajima, N., Tamura, J., Kobayashi, I., et al. (2001). Inflammatory cytokines in vitreous fluid and serum of patients with diabetic vitreoretinopathy. J. Diabetes Complications 15, 257-259. doi: 10.1016/ S1056-8727(01)00155-6

Zamboni, M., Di Francesco, V., Garbin, U., Fratta Pasini, A., Mazzali, G., Stranieri, C., et al. (2007). Adiponectin gene expression and adipocyte $\mathrm{NF}-\kappa \mathrm{B}$ transcriptional activity in elderly overweight and obese women: inter-relationships with fat distribution, hs-CRP, leptin and insulin resistance. Int. J. Obes. 31, 1104-1109. doi: 10.1038/sj.ijo. 0803563

Zhang, K., Ferreyra, H. A., Grob, S., Bedell, M., and Zhang, J. J. (2012). Diabetic Retinopathy: Genetics and Etiologic Mechanisms, 5th Edn, ed. D. R. Hinton. London: Elsevier Saunders. doi: 10.1016/B978-1-4557-0737-9.00046-1

Zhang, L., Dai, S. Z., Nie, X. D., Zhu, L., Xing, F., and Wang, L. Y. (2013). Effect of Salvia miltiorrhiza on retinopathy. Asian Pac. J. Trop. Med. 6, 145-149. doi: 10.1016/S1995-7645(13)60011-5

Zhang, X., Saaddine, J. B., Chou, C.-F., Cotch, M. F., Cheng, Y. J., Geiss, L. S., et al. (2010). Prevalence of diabetic retinopathy in the United States, 2005-2008. JAMA 304, 649-656. doi: 10.1001/jama.2010.1111

Zhang, Z., Yuan, W., Sun, L., Szeto, F. L., Wong, K. E., Li, X., et al. (2007). 1,25-Dihydroxyvitamin D3 targeting of NF- $\kappa$ B suppresses high glucoseinduced MCP-1 expression in mesangial cells. Kidney Int. 72, 193-201. doi: 10.1038/sj.ki.5002296

Zhao, Y., Krishnamurthy, B., Mollah, Z. U., Kay, T. W., and Thomas, H. E. (2011). NF-кB in type 1 diabetes. Inflamm. Allergy Drug Targets 10, 208-217. doi: 10.2174/187152811795564046

Zheng, C., Yin, Q., and Wu, H. (2010). Structural studies of NF-кB signaling. Cell Res. 21, 183-195. doi: 10.1038/cr.2010.171

Zhu, S.-H., Liu, B.-Q., Hao, M.-J., Fan, Y.-X., Qian, C., Teng, P., et al. (2017). Paeoniflorin suppressed high glucose-induced retinal microglia MMP9 expression and inflammatory response via inhibition of TLR4/NF-кB pathway through upregulation of SOCS3 in diabetic retinopathy. Inflammation doi: 10.1007/s10753-017-0571-z [Epub ahead of print].

Conflict of Interest Statement: The authors declare that the research was conducted in the absence of any commercial or financial relationships that could be construed as a potential conflict of interest.

The reviewers ED, AT and handling Editor declared their shared affiliation.

Copyright (c) 2017 Suryavanshi and Kulkarni. This is an open-access article distributed under the terms of the Creative Commons Attribution License (CC BY). The use, distribution or reproduction in other forums is permitted, provided the original author(s) or licensor are credited and that the original publication in this journal is cited, in accordance with accepted academic practice. No use, distribution or reproduction is permitted which does not comply with these terms. 